\title{
Conhecimento e uso de recursos vegetais de restinga por comunidades das ilhas do Cardoso (SP) e de Santa Catarina (SC), Brasil
}

\author{
Tatiana Mota Miranda ${ }^{1}$ e Natalia Hanazaki ${ }^{2,3}$
}

Recebido em 15/01/2007. Aceito em 24/05/2007

\begin{abstract}
RESUMO - (Conhecimento e uso de recursos vegetais de restinga por comunidades das ilhas do Cardoso (SP) e de Santa Catarina (SC), Brasil). Este trabalho tem como objetivo investigar a etnobotânica de comunidades litorâneas em áreas de restinga, analisando o uso de recursos vegetais para fins alimentares, medicinais e manufatureiros, além de investigar a atual situação de dois grupos populacionais quanto ao conhecimento e uso dos recursos vegetais locais, comparando também as maneiras com que ambos os grupos (caiçaras e residentes de áreas de influência da colonização açoriana), com modos de vida semelhantes, mas de origem e localização geográfica distintas, utilizam os recursos naturais de que dispõem. O estudo foi realizado em cinco comunidades de duas regiões onde a vegetação de restinga arbórea está presente: a Ilha do Cardoso (SP) e a porção sul da Ilha de Santa Catarina (SC). Apesar de suas semelhanças quanto à sua localização em ambientes insulares com acesso à vegetação de restinga e ao seu modo de vida, existem padrões de uso de recursos distintos entre os grupos estudados. Concluiu-se também que os caiçaras da Ilha do Cardoso possuem uma identidade cultural mais evidente, além de um conhecimento acerca dos recursos vegetais mais diverso e associado à vegetação de restinga, situação distinta da encontrada entre os descendentes de açorianos da Ilha de Santa Catarina.
\end{abstract}

Palavras-chave: Etnobotânica, Conhecimento local, Mata Atlântica, Caiçaras, Açorianos

\begin{abstract}
Knowledge and use of coastal sand-dune plant resources by communities from Cardoso (São Paulo) and Santa Catarina (Santa Catarina) islands, Brazil). This study aims to investigate the ethnobotany of coastal communities in areas of restinga (coastal sand-dune vegetation). We analyze the use of plants for medicinal, food and handicraft purposes and investigate the current situation of two local populations with similar livelihoods, but with distinct origins and geographic location, concerning their knowledge and use of plants. We compare the way both groups (caiçaras and descendants of Azorian settlers) use plant resources. This study was conducted in five communities from two regions where restinga vegetation is present: Cardoso Island (São Paulo) and the southern part of Santa Catarina Island (Santa Catarina). In spite of similarities regarding livelihood and geographic location in insular environments with access to coastal sand-dune vegetation, there are distinct forms of use of plant resources in these two groups. In addition, we concluded that the caiçaras from Cardoso Island have a stronger cultural identity and a distinct knowledge of plant resources when compared to descendants of Azorian settlements in Brazil; this knowledge is more diverse and associated with the restinga.
\end{abstract}

Key words: Ethnobotany, Local knowledge, Atlantic Forest, Caiçara, Azorian

\section{Introdução}

A restinga brasileira é um ecossistema costeiro, composto por um conjunto diversificado de comunidades biológicas, distintas florística e fisionomicamente, comuns em solos arenosos pouco desenvolvidos, formando complexos vegetacionais pioneiros. Compreende fisionomias originalmente herbáceas/subarbustivas, arbustivas ou arbóreas, que variam de acordo com a inundação do terreno e o teor da salinidade. Pode apresentar-se em mosaico ou em certa zonação, geralmente no sentido oceano- continente, ocorrendo aumento tanto da lenhosidade e da altura da vegetação, como também do número de espécies ocorrentes (Barros et al. 1991; Falkenberg 1999; Sampaio et al. 2005).

Esse ecossistema foi historicamente utilizado por populações humanas que ocupam a região costeira, incluindo várias populações urbanas ao longo do litoral brasileiro. Nessa região costeira encontram-se também pelo menos cinco tipos de comunidades tradicionais, de modos de vida bastante semelhantes, porém de distintas origens (Diegues \& Arruda 2001; Willems 2003). Tais populações caracterizam-se por possuírem

\footnotetext{
1 Universidade Federal de Santa Catarina, Departamento de Botânica, Centro de Ciências Biológicas, Programa de Pós-graduação em Biologia Vegetal, 88040-970 Florianópolis, SC, Brasil (tmotam@yahoo.com.br)

2 Universidade Federal de Santa Catarina, Departamento de Ecologia e Zoologia, Centro de Ciência Biológicas, 88010-970 Florianópolis, SC, Brasil

3 Autor para correspondência: natalia@ccb.ufsc.br
} 
conhecimentos, práticas e crenças próprios e intimamente relacionados a processos adaptativos, envolvendo as relações entre os seres vivos e seu ambiente, conhecimento este que enfatiza a dependência de sociedades aos recursos locais (Berkes et al. 1995; Berkes 1999). No litoral sudeste e sul do Brasil existem, respectivamente, grupos populacionais de origem caiçara e açoriana, que habitam áreas de Restinga da Mata Atlântica.

O presente trabalho pretende aprofundar o estudo das relações entre esses dois tipos de grupos populacionais, de origem caiçara e açoriana, e a Restinga em que habitam, ampliando o conhecimento acerca da cultura de cada um deles, valendo-se de abordagem contemporânea da Etnobotânica (Davis 1995). Partindo-se do pressuposto de que, em face da grande diversidade biológica da Mata Atlântica (Myers et al. 2000), os grupos estudados que interagem diretamente com este bioma podem acumular amplo conhecimento sobre suas espécies vegetais e que, apesar de distintas em relação à origem, as comunidades caiçaras e as de influência açoriana podem apresentar um padrão similar de uso do ambiente florestal, buscou-se descrever e analisar o conhecimento e o uso de plantas por comunidades locais, de influências caiçara e açoriana, habitando áreas onde se encontra vegetação de restinga. Partindo do pressuposto de que, se o conhecimento etnobotânico reflete as interações entre pessoas e os recursos vegetais disponíveis no ambiente, seja em função da abundância e/ou da aparência (Stagegaard et al. 2002; Albuquerque \& Lucena 2005) destes recursos, então espera-se encontrar um conhecimento similar entre comunidades humanas vivendo em situações ambientais similares. Entretanto, quando assumimos que este conhecimento é fortemente mediado pelo contexto local atual e histórico, numa escala mais fina de análise, espera-se encontrar um conhecimento mais particularizado. Especificamente, buscou-se: a) efetuar um registro comparativo das plantas conhecidas e utilizadas por comunidades dos dois grupos populacionais; b) analisar a distribuição do conhecimento nas e entre as comunidades; c) comparar o conhecimento etnobotânico nas diferentes áreas de estudo.

Estudos etnobotânicos de natureza comparativa e/ou quantitativa foram também realizados em outras comunidades caiçaras do litoral brasileiro como na Ilha de Búzios (Begossi et al. 1993; 2002a); em Gamboa (Figueiredo et al. 1993); em Puruba e Picinguaba (Rossato et al. 1999); em Almada e Camburí (Hanazaki et al. 1996; 2000); e em Arraial do Cabo (FonsecaKruel \& Peixoto 2004), assim como em outras localidades do Brasil e do mundo (veja, por exemplo, Toledo et al. 1995; Lawrence et al. 2005; Williams et al. 2005; Pieroni \& Quave 2005; Silva \& Andrade 2005). A importância desse tipo de investigação reside no fato de, ao possibilitar comparações entre diferentes áreas de estudo, facilita a descoberta de distintos padrões de uso de um mesmo tipo vegetacional, além de auxiliar no entendimento da dinâmica do conhecimento dos grupos humanos pesquisados, aspectos fundamentais quando se busca a conservação dos recursos vegetais e do conhecimento local acerca dos mesmos. É oportuno ressaltar também que, diferentemente do que ocorre com populações caiçaras, são escassos os estudos etnobotânicos evolvendo comunidades de influência açoriana.

\section{Material e métodos}

Áreas de estudo - A Ilha do Cardoso pertence ao município de Cananéia, litoral sul do Estado de São Paulo. Abrange uma área de $22.500 \mathrm{ha}$, sendo constituído por áreas de Floresta Pluvial de Encosta e Planície, Manguezal e Restinga (Sampaio et al. 2005). Toda a sua área corresponde ao Parque Estadual da Ilha do Cardoso (PEIC). Dentro desta unidade de conservação encontram-se habitantes nativos indígenas (Guarani) e caiçaras, distribuídos em diversos núcleos populacionais. Os caiçaras são habitantes rurais nativos da Floresta Atlântica fruto da miscigenação entre índios e portugueses (Begossi 1998), que habitam a região que se estende do litoral norte do Paraná ao litoral sul do Rio de Janeiro. No presente estudo foram selecionadas as comunidades de Pereirinha, Itacuruçá, Foles e Cambriú, por estarem estabelecidas em áreas com mata de restinga (Fig. 1). Estas comunidades caracterizam-se pelo reduzido número de habitantes (respectivamente, 12, 18, 19 e 49 moradores, incluindo crianças e jovens), que têm na pesca, no turismo e nas atividades ligadas ao PEIC suas principais atividades econômicas. O número de entrevistados em cada uma delas foi, respectivamente, 9, 11, 8 e 23.

$\mathrm{Na}$ Ilha de Santa Catarina, assim como no litoral sul do país, são encontradas comunidades costeiras, de influência açoriana, que resultaram de um fluxo de imigração do arquipélago dos Açores para o Brasil ocorrido em meados do século XVIII (Diegues \& Arruda 2001; Ribeiro 2004). Na porção sul da Ilha de Santa Catarina, inserida no Parque Estadual da Serra do Tabuleiro (PEST), localiza-se a comunidade de 


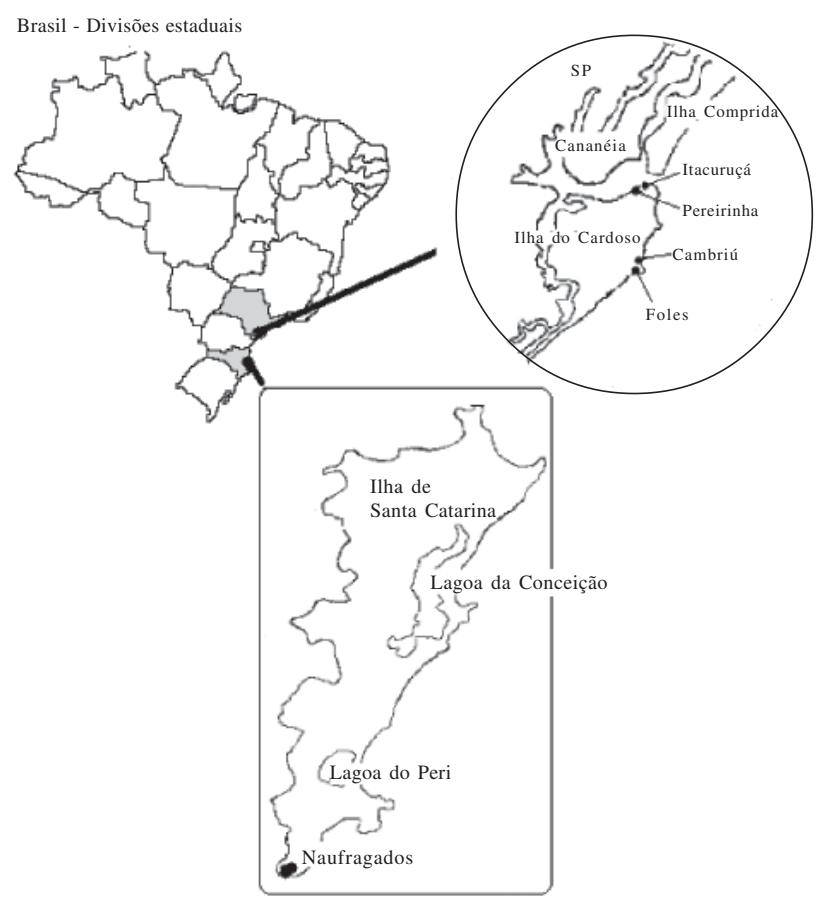

Figura 1. Localização das comunidades estudadas (Fonte: Mapa da Ilha do Cardoso: adaptado do Instituto de Pesca - Núcleo de Pesquisa e Desenvolvimento do Litoral Sul do Estado de São Paulo, 2004; Mapa da Ilha de Santa Catarina: adaptado da Tese de Mestrado "Parque Estadual da Serra do Tabuleiro: território institucionalizado e lugar de vivência". Programa de Pós-Graduação em Geografia, UFSC, Florianópolis, 2002; Mapa do Brasil: adaptado de www.abcd.org.br, acessado em dezembro de 2006).

Naufragados (Fig. 1), que por sua origem pode ser considerada de influência açoriana, tendo sido formada por uma colônia de pescadores e posseiros ocasionais (A. Reis, dados não publicados). Atualmente, Naufragados conta com cerca de 20 moradores que, além da prática da pesca e de atividades relacionadas ao turismo, prestam serviços como autônomos no município de Florianópolis e seus arredores. Em Naufragados foram entrevistados 12 moradores. Nas etapas preliminares deste estudo, verificamos que, na Ilha de Santa Catarina, Naufragados foi a única comunidade que se assemelhava àquelas selecionadas na Ilha do Cardoso, por apresentar interface com a vegetação de restinga, relativo isolamento de centros urbanos, e sobreposição com uma unidade de conservação estadual.

Coleta de dados - Foi efetuado um contato inicial com as comunidades em março e abril/2004, para esclarecimentos sobre o intuito da pesquisa e solicitação de autorização informal para a sua realização. A coleta de dados foi efetuada entre agosto e setembro/2004 e janeiro e fevereiro/2005, na Ilha do Cardoso, e entre março/2004 e dezembro/2005 na Ilha de Santa Catarina. A coleta de dados consistiu na realização de entrevistas semi-estruturadas com os moradores, residentes no local há pelo menos cinco anos, maiores de 18 anos, de ambos os sexos, que se dispuseram a participar da pesquisa. Esses parâmetros foram estabelecidos de acordo com outras pesquisas etnobotânicas realizadas com caiçaras (Hanazaki et al. 1996; 2000; Begossi et al. 2002a). As entrevistas, que ocorriam individualmente, continham questões relativas a aspectos sócio-econômicos dos entrevistados (idade, sexo, escolaridade, origem, tempo de residência no local, estado civil, número de residentes na casa e atividade desenvolvida) e ao conhecimento sobre os recursos vegetais da região e seus respectivos usos locais.

Os moradores entrevistados foram solicitados a nomear as plantas que conheciam e a indicar-lhes as suas respectivas utilidades, assim como informações sobre o ambiente em que ocorriam, se a planta já havia sido usada e se era cultivada. As informações foram anotadas pela entrevistadora nas fichas de campo no momento da entrevista e as plantas foram categorizadas nos seguintes grupos de finalidades: manufatura, alimentação, medicina e outros. A categoria "manufaturas" inclui as plantas empregadas na confecção de artesanatos, na construção de casas e na fabricação de canoas. Na categoria "outros" foram incluídas as espécies usadas como ornamentação e/ou alimento da fauna. Tais categorias foram aqui estabelecidas como as mais usuais, tendo como referência outros estudos etnobotânicos (Prance et al. 1987; Figueiredo et al. 1993; Hanazaki et al. 2000).

No momento da entrevista procurou-se realizar a coleta das plantas citadas. Nos casos das plantas de localização em sítios distantes ou de difícil acesso, solicitava-se ao entrevistado ou a outro morador que igualmente conhecesse a planta citada, que indicasse onde a planta poderia ser encontrada e que participasse também das coletas, nas quais foram recolhidas amostras preferencialmente reprodutivas das espécies. A coleta do material botânico atendeu aos padrões metodológicos definidos para estudos etnobotânicos (Ming 1996), sendo estes posteriormente herborizados, identificados e depositados nos Herbários ESA (ESALQ/USP) e FLOR (UFSC), bem como incorporado ao acervo do Laboratório de Ecologia Humana e Etnobotânica (Departamento de Ecologia e Zoologia, UFSC). A identificação botânica foi feita pelo Prof. Dr. Daniel Falkenberg (Departamento de Botânica, UFSC). 
Análise dos dados - Os dados foram analisados qualitativa e quantitativamente, por meio de ferramentas utilizadas em etnobotânica (Hanazaki et al. 1996; Begossi et al. 2002b). Primeiramente efetuou-se a descrição geral das espécies utilizadas pelas cinco comunidades, considerando-se: o número de etnoespécies citadas; as espécies e famílias botânicas; seu local de origem e a(s) categoria(s) de uso das espécies citadas. O termo etnoespécie é aqui empregado como sinônimo de nome popular de uma planta. $\mathrm{O}$ termo origem refere-se, neste trabalho, ao local em que a planta ocorre naturalmente, sendo, como tal, considerada: planta nativa (de restinga e/ou áreas do domínio mata atlântica) e planta exótica (oriundas de outras áreas).

Foram efetuadas análises multivariadas (Höft et al. 1999; Valentin 1995; 2002; Peroni 2002) através de agrupamentos, com intuito de verificar a existência de similaridades quanto ao uso e ao conhecimento dos recursos vegetais pelas comunidades de Pereirinha, Itacuruçá, Foles e Cambriú, na Ilha do Cardoso (SP) e Naufragados, na Ilha de Santa Catarina (SC). Segundo Valentin (1995), os agrupamentos consistem reconhecer entre unidades amostrais um grau de similaridade suficiente para reuni-los num mesmo conjunto. Foram efetuados dois agrupamentos distintos, nos quais se consideraram as comunidades ou entrevistados como unidades amostrais e as plantas citadas como variáveis. No primeiro agrupamento, construído a partir de uma matriz de frequiências relativas de cada planta citada por comunidade (número de citações de cada planta dividido pelo número total de citações), optou-se pelo emprego do coeficiente de distância Bray Curtis (devido à natureza quantitativa dos dados e por este não considerar as duplas-ausências e ser influenciado pelas espécies dominantes) (Valentin 1995; 2000) sendo o método de agrupamento escolhido o UPGMA (por apresentar menor grau de distorção dos dados) (Valentin 1995). O segundo agrupamento, construído a partir de uma matriz de presença e ausência da citação de cada planta por entrevistado, foi efetuado através do coeficiente de similaridade de Sørensen (devido à natureza binária dos dados, a não consideração das duplas-ausências e por dar peso àquilo que está realmente presente na amostra) (Valentin 1995; 2000) e do método UPGMA. Para estas análises utilizou-se o programa FITOPAC 1 for Windows, de autoria de prof. G.J. Shepherd (Departamento de Botânica, UNICAMP).

Tendo em vista que a diversidade envolve tanto a riqueza de espécies de determinado local como a forma pela qual elas se encontram distribuídas (abundância ou equitabilidade), ela pode ser expressa por meio de índices (Krebs 1989) que permitem comparações objetivas entre o conhecimento local em diferentes comunidades e são ferramentas úteis ao entendimento da dinâmica deste conhecimento (Begossi 1996). O método da rarefação, que permite estimar o número esperado de espécies em determinada amostra, complementa a utilização de tais índices quando as unidades amostrais têm tamanhos diferentes. Foram calculados os índices de diversidade de Shannon-Wiener $\left(H^{\prime}\right)$ e de Simpson $(1 / D)$; os de equitabilidade de Shannon-Wiener $(\mathrm{E})$ e de Simpson $\left(\mathrm{E}_{1 / \mathrm{D}}\right)$ (Magurran 1988; Krebs 1989; Zar 1996) e as curvas de rarefação (Colwell 2005) utilizando-se o número de citações de cada etnoespécie. Comparações estatísticas dos índices de Shannon-Wiener foram feitas com a utilização do teste $t$ (Zar 1996). Testes chi-quadrado (Zar 1996) foram usados para comparações entre características sócio-econômicas das comunidades (a partir do número de entrevistados para cada descritor sócio-econômico) e entre categorias de plantas nativas e exóticas (a partir do número de plantas nativas e exóticas citadas em cada comunidade).

\section{Resultados e discussão}

Características das populações estudadas - Foram entrevistados 63 moradores: 51 residentes na Ilha do Cardoso e 12 na comunidade de Naufragados, Ilha de Santa Catarina. Considerando-se o reduzido tamanho de cada comunidade, sua proximidade geográfica e as relações de parentesco de seus habitantes, as comunidades foram reunidas nos três seguintes grupos: 1) Pereirinha e Itacuruçá $(\mathrm{n}=20) ; 2)$ Foles e Cambriú $(\mathrm{n}=31) ; 3)$ Naufragados $(\mathrm{n}=12)$ (Tab. 1).

O cálculo do teste chi-quadrado para independência revelou que há diferença entre os grupos de entrevistados apenas quanto à origem $\left(\chi^{2}=52,59\right.$, $\mathrm{p}<0,05,2$ graus de liberdade), uma vez que em Naufragados todos os entrevistados não são nativos do local, contrastando com as comunidades da Ilha do Cardoso. Os grupos de entrevistados não foram diferentes para as proporções de $\operatorname{sexo}\left(\chi^{2}=0,23, p>0,05,2\right.$ g.l.), faixas etárias $\left(\chi^{2}=7,40, \mathrm{p}>0,05,8 \mathrm{~g} .1\right.$. $)$, tempo de residência $\left(\chi^{2}=5,01, \mathrm{p}>0,05,2\right.$ g.1.) e escolaridade $\left(\chi^{2}=8,75\right.$, $\mathrm{p}>0,05,4$ g.1.). Entende-se aqui "nativos do local" os moradores que nasceram nas próprias comunidades. Apesar de não nascida na praia de Naufragados, a maioria de seus moradores veio de outras localidades que também sofreram influência da cultura açoriana. 
Tabela 1. Características sócio-econômicas dos 63 entrevistados nas comunidades da Ilha do Cardoso (SP) e Ilha de Santa Catarina (SC), Brasil.

\begin{tabular}{|c|c|c|c|c|}
\hline \multirow[t]{2}{*}{ Dados sócio-econômicos } & & \multicolumn{3}{|c|}{ Grupos de Comunidades } \\
\hline & & Pereirinha-Itacuruçá & Cambriú-Foles & Naufragados \\
\hline \multirow[t]{2}{*}{ Sexo } & Masculino & $55 \%$ & $58 \%$ & $50 \%$ \\
\hline & Feminino & $45 \%$ & $42 \%$ & $50 \%$ \\
\hline \multirow[t]{5}{*}{ Faixas etárias } & 18 a 30 anos & $50 \%$ & $45 \%$ & $25 \%$ \\
\hline & 31 a 40 anos & $5 \%$ & $13 \%$ & $8 \%$ \\
\hline & 41 a 50 anos & $15 \%$ & $26 \%$ & $25 \%$ \\
\hline & 51 a 60 anos & $20 \%$ & $3 \%$ & $25 \%$ \\
\hline & $\geq 61$ anos & $10 \%$ & $13 \%$ & $17 \%$ \\
\hline \multirow[t]{2}{*}{ Origem } & Local & $90 \%$ & $100 \%$ & $0 \%$ \\
\hline & Externa & $10 \%$ & $0 \%$ & $100 \% * *$ \\
\hline \multirow[t]{2}{*}{ Tempo de residência no local } & $<$ de 10 anos & $95 \%$ & $87 \%$ & $67 \%$ \\
\hline & $>$ de 10 anos & $5 \%$ & $13 \% *$ & $33 \%$ \\
\hline \multirow[t]{3}{*}{ Escolaridade } & Ensino Fundamental & $65 \%$ & $84 \%$ & $75 \%$ \\
\hline & Ensino Médio & $30 \%$ & $3 \%$ & $8 \%$ \\
\hline & Analfabeto(a) & $5 \%$ & $13 \%$ & $17 \%$ \\
\hline Entrevistas & & 20 & 31 & 12 \\
\hline
\end{tabular}

*oriundos de praias vizinhas ao PEIC; **oriundos de outras localidades de Florianópolis, municípios vizinhos e, no caso de um entrevistado, de outro país.

Para $60 \%$ dos moradores de Pereirnha e Itacuruçá o turismo é a atividade principal, seguido da pesca (30\%), de atribuições ligadas a cargo público $(15 \%)$ e da execução de afazeres domésticos $(1 \%)$. Em relação ao vínculo empregatício, $50 \%$ são funcionários do PEIC, onde trabalham como monitores e vigias. Já em Cambriú/Foles, a principal atividade desenvolvida pelos moradores é a pesca (54\%), com $13 \%$ deles se ocupando com o turismo. A execução dos afazeres domésticos constitui a principal ocupação para $42 \%$ das mulheres. Em Naufragados, $42 \%$ dos entrevistados vivem da pesca; $33 \%$ atuam como empregados autônomos, como vigias e faxineiras e $25 \%$ desenvolvem atividades relacionadas ao turismo. $33 \%$ das mulheres ocupam-se com afazeres domésticos (alguns moradores possuem mais de uma atividade e foram considerados em cada uma delas, razão pela qual a soma das porcentagens ultrapassa $100 \%$ ).

Principais espécies vegetais utilizadas - Os 63 entrevistados citaram 264 etnoespécies, correspondentes a 201 espécies pertencentes a 76 famílias botânicas. Considerando a origem, apuraram-se 111 plantas nativas e 109 exóticas. A diferença numérica entre o total de espécies identificadas (264) e o total de plantas com origem estabelecida (220) resultou da impossibilidade de se estabeler a origem de parte das etnoespécies. As famílias botânicas com maior número de espécies foram Myrtaceae (25 espécies);
Asteraceae (18 espécies), Poaceae (17 espécies), Lamiaceae (12 espécies), Euphorbiaceae (10 espécies), Arecaceae e Rutaceae (as duas últimas com nove espécies cada). Ao estudar comunidades caiçaras do município de Ubatuba, litoral norte de São Paulo, Hanazaki et al. (2000), entrevistaram 102 moradores locais, os quais citaram 227 etnoespécies, correspondentes a 214 espécies, pertencentes a 74 famílias botânicas, sendo Asteraceae, Lamiaceae, Poaceae, Euphorbiaceae, Myrtaceae e Bignoniaceae, as mais mencionadas. Esse resultado mostra-se semelhante ao encontrado no presente estudo, exceto para a maior quantidade de espécies da família Myrtaceae. Entretanto, entre os 58 caiçaras entrevistados na comunidade de Gamboa, litoral sul do Rio de Janeiro, Figueiredo et al. (1993) catalogaram 90 espécies de 40 famílias botânicas, onde se destacaram Rutaceae, Asteraceae, Lamiaceae e Solanaceae, situação distinta das anteriormente apontadas. Outro estudo, realizado também em área de restinga, investigou o conhecimento de 15 pescadores artesanais residentes no entorno da Praia Grande, litoral do Rio de Janeiro, obtendo um total de 68 espécies científicas, distribuídas em 42 famílias botânicas das quais se destacaram Myrtaceae, Asteraceae, Cactaceae, Anacardiaceae e Leguninosae (Fonseca-Kruel \& Peixoto 2004). Estes trabalhos indicam para uma possível tendência a um maior número de espécies das famílias Myrtaceae e 
Asteraceae quando se trata de ambientes de restinga, em comparação a comunidades litorâneas que ocupam outros subtipos de formações de Mata Atlântica.

$\mathrm{Na}$ catalogação das etnoespécies, notaram-se as ocorrências de: a) homonimia (um mesmo nome popular para designar plantas de espécies diferentes. Exemplo: hortelã - utilizado para designar Mentha arvensis L. e Mentha sp.; boldo - empregado para designar Plectranthus barbatus Andrews, Vernonia condensata Baker e Salvia sp.); e b) sinonimia (vários nomes populares pelos quais se denominam uma única espécie. Exemplo: capim-limão, capim-cidró e ervacidreira, todos utilizados para designar Cymbopogon citratus (DC.) Stapf.).

As plantas mais citadas pelos entrevistados foram, respectivamente, o guarapuvu ou guapiruvu (Schizolobium parahyba (Vell.) S. F. Blake) lembrado por 55\% ( $\mathrm{n}=35)$ deles; a hortelã (Mentha arvensis L. e Mentha sp.) por $51 \%(\mathrm{n}=32)$; o boldo (Plectranthus barbatus Andrews, Vernonia condensata Baker; Salvia sp.) por $49 \%$ (n = 31), o araçá (Psidium cattleyanum Sabine) por $40 \%(n=25)$ e a caxeta (Tabebuia cassinoides (Lam.) DC.) $(\mathrm{n}=24)$ por $38 \%$ dos entrevistados (Tab. 2). As plantas que figuram entre as mais citadas são também usadas por outras comunidades caiçaras do litoral norte e sul do Estado de São Paulo e do litoral do Rio de Janeiro (Figueiredo et al. 1993; Hanazaki et al. 1996; 2000; Begossi et al. 2002a; Fonseca-Kruel \& Peixoto 2004).

Comparações entre comunidades - No primeiro agrupamento as comunidades foram analisadas de acordo com o conjunto de plantas citadas em cada uma delas, com base em sua freqüência relativa (Fig. 2). Constatou-se a existência de dois grupos: o primeiro constituído pelos moradores de Naufragados e o segundo, mais amplo, pelos moradores da Ilha do Cardoso. Este segundo grupo é composto por dois subgrupos: 1) Pereirinha e Itacuruçá; 2) Foles e Cambriú. Desta forma, o que reúne as comunidades em um mesmo subgrupo é sua similaridade quanto ao conjunto de plantas citadas. Portanto, os conjuntos de plantas citados nas comunidades apresentam sutis diferenças, separando-as em subgrupos que são coerentes com sua proximidade geográfica e relações de parentesco (Fig. 2).

No segundo agrupamento, os entrevistados foram classificados segundo as plantas por eles citadas. No geral a similaridade entre os entrevistados é grande, pois não existe uma separação nítida de grupos. Há uma tênue tendência para a formação de quatro grupos: a maioria dos moradores de Naufragados aparece isolada num primeiro grupo mais externo (Fig. 3: 3N; 7N; 1N; 5N; 12N; 2N; 4N; 11N). Um segundo grupo reúne a maioria dos moradores de Pereirinha/Itacuruçá (Fig. 3: 26PI; 28PI; 30PI; 27PI; 49PI; 33PI; 6N; 14PI; 29PI; 18PI; 20PI; 19PI; 23PI; 25PI; 15PI; 21PI; 13PI; 16PI; 17PI; 24PI). Já os moradores de Cambriú/Foles misturam-se parte com moradores de Pereirinha/ Itacuruçá, constituindo um terceiro grupo (Fig. 3: 31PI; 32PI; 22PI; 44FC; 56FC; 35FC; 36FC; 46FC; 38FC; 60FC; 34FC; 61FC; 40FC; 39FC) e parte com moradores de Naufragados, constituindo um quarto grupo menos definido, de posição intermediária entre o primeiro e o segundo e terceiro grupos (Fig. 3: 41FC; 48FC; 55FC; 58FC; 47FC; 59FC; 10N; 37FC; 9N; 8N; 52FC; 62FC; 53FC; 63FC; 45FC; 54FC; 57FC; 51C; 42FC; 43FC; 50FC). Para o conjunto de plantas mencionadas, tal resultado reflete a maior semelhança entre alguns moradores de Cambriú/Foles com os de Naufragados, assim como com os de Pereirinha/ Itacuruçá, e comprova a menor similaridade entre os moradores de Pereirinha/Itacuruçá com os de Naufragados (Fig. 3).

Técnicas multivariadas também foram uma das ferramentas empregadas na análise sobre as práticas de manejo em quintais da vila rural de São Rafael, na região do semi-árido mexicano (Blanckaert et al. 2004). A composição florística de 30 quintais foi analisada através de agrupamentos por UPGMA, baseado na presença/ausência de espécies em cada quintal. O agrupamento indicou a inexistência de um padrão claro na composição florística dos quintais, representada pela não formação de grupos bem definidos deles, entretanto com uma tendência na formação de subgrupos reunidos por sutis semelhanças como, por exemplo, a presença de espécies frutíferas de grande porte na maioria dos quintais (Blanckaert et al. 2004). Análises de agrupamento mostram-se bastante promissoras em estudos etnobotânicos, não somente no entendimento do conhecimento dos moradores sobre plantas, mas também no entendimento da composição florística de quintais e, quando utilizadas adequadamente, podem elucidar minúcias e sutilezas presentes nas relações entre grupos humanos e os recursos vegetais.

Etnobotânica e diversidade nos grupos estudados Comparando com os dados agregados, a maior citação de Myrtaceae confirma-se apenas para Pereirinha/ Itacuruçá. As famílias botânicas com maior número de espécies em Pereirinha/Itacuruçá foram Myrtaceae 
Tabela 2. Plantas conhecidas, utilizadas e citadas por, no mínimo, seis moradores (número correspondente a aproximados $10 \%$ do total dos entrevistados). Local: N - Naufragados; PI - Pereirinha/Itacuruçá; FC - Foles/Cambriú. Usos: 1 - Manufatura; 2- Medicamento; 3 - Alimento; 4 - Outros.

\begin{tabular}{|c|c|c|c|c|c|c|c|}
\hline \multirow[t]{2}{*}{ Etnoespécie } & \multirow[t]{2}{*}{ Espécie botânica } & \multirow[t]{2}{*}{ Família } & \multirow[t]{2}{*}{ Status } & \multicolumn{3}{|c|}{$\mathrm{N}^{\circ}$ citações } & \multirow[t]{2}{*}{ Uso } \\
\hline & & & & $\mathrm{N}$ & PI & $\mathrm{FC}$ & \\
\hline abacate & Persea americana Mill. & Lauraceae & exótica & 3 & 5 & 7 & $2-3$ \\
\hline aipim/mandioca $* * *$ & Manihot esculenta Crantz & Euphorbiaceae & exótica & 2 & 4 & 10 & 3 \\
\hline aipo & Apium sp. & Apiaceae & nativa & 0 & 2 & 5 & 2 \\
\hline ananás-de-raposa & indet. 1 & Bromeliaceae & nativa & 0 & 9 & 0 & $2-3$ \\
\hline araçá/araçá-roxo*** & Psidium cattleyanum Sabine & Myrtaceae & nativa & 3 & 14 & 8 & $1-2-3$ \\
\hline araticum & $\begin{array}{l}\text { Annona crassifolia Mart. } \\
\text { Rollinia sericea (R.E. Fr.) R.E. }\end{array}$ & $\begin{array}{l}\text { Annonaceae } \\
\text { Annonaceae }\end{array}$ & $\begin{array}{l}\text { nativa } \\
\text { nativa }\end{array}$ & 1 & 3 & 7 & $2-3$ \\
\hline aroeira & Schinus terebinthifolia Raddi & Anacardiaceae & nativa & 1 & 6 & 2 & $1-2-4$ \\
\hline babosa & Aloe sp. & Liliaceae & exótica & 6 & 4 & 0 & 2 \\
\hline banana & Musa acuminata Colla & Musaceae & exótica & 4 & 1 & 8 & $2-3$ \\
\hline boldo** & indet. 2 & Asteraceae & exótica & 10 & 9 & 12 & 2 \\
\hline & Plectranthus barbatus Andrews & Lamiaceae & exótica & & & & \\
\hline & Salvia sp. & Lamiaceae & exótica & & & & \\
\hline brejaúva & $\begin{array}{l}\text { Astrocaryum aculeatissimum } \\
\text { (Schott) Burret }\end{array}$ & Arecaceae & nativa & 0 & 5 & 5 & $1-3$ \\
\hline caju/caju branco $* * *$ & Anacardium occidentale $\mathrm{L}$. & Anacardiaceae & nativa & 4 & 5 & 5 & $2-3$ \\
\hline cana-do-brejo & Costus spiralis (Jacq.) Roscoe & Zimgiberaceae & nativa & 0 & 7 & 2 & $2-3$ \\
\hline canela & Inga sp. & Mimosaceae & nativa & 0 & 4 & 6 & 1 \\
\hline $\begin{array}{l}\text { capim-cidró/capim-limão/ } \\
\text { erva-cidreira**** }\end{array}$ & Cymbopogon citratus (DC.) Stapf. & Poaceae & exótica & 7 & 6 & 11 & 2 \\
\hline cará & Dioscorea alata L. & Dioscoriaceae & exótica & 0 & 0 & 6 & 3 \\
\hline carqueja & Baccharis trimera (Less.) DC. & Asteraceae & nativa & 1 & 6 & 0 & 2 \\
\hline cataia & $\begin{array}{l}\text { Pimenta pseudocaryophyllus (Gomes) } \\
\text { Landrum }\end{array}$ & Myrtaceae & nativa & 0 & 13 & 0 & 2 \\
\hline caxeta & Tabebuia cassinoides (Lam.) A.P. DC. & Bignoniaceae & nativa & 0 & 11 & 13 & 1 \\
\hline cedro & Cedrela sp. 2 & Meliaceae & indet. & 1 & 1 & 4 & 1 \\
\hline cipó-caboclo & indet. 3 & indet. & nativa & 0 & 5 & 1 & 2 \\
\hline cipó-timbopeva & indet. 4 & Sapindaceae & nativa & 0 & 9 & 0 & 1 \\
\hline erva-baleeira/mentruz/saliana*** & Cordia verbenacea DC. & Boraginaceae & nativa & 1 & 7 & 2 & 2 \\
\hline erva-de-santa-maria & Chenopodium ambrosioides $\mathrm{L}$. & Chenopodiaceae & nativa & 0 & 9 & 10 & 2 \\
\hline erva-do-bicho & indet. 5 & Polygonaceae & exótica & 0 & 4 & 2 & 2 \\
\hline feijão & Phaseolus vulgaris $\mathrm{L}$. & Fabaceae & exótica & 0 & 3 & 3 & 3 \\
\hline figueira & Ficus insipida Willd & Moraceae & nativa & 1 & 3 & 2 & $1-2-3-4$ \\
\hline garapuvu/guapiruvu*** & Schizolobium parayba (Vell.) Blake & Caesalpiniaceae & nativa & 0 & 17 & 18 & $1-2-4$ \\
\hline $\begin{array}{l}\text { goiaba/goiaba branca/goiaba } \\
\text { vermelha*** }\end{array}$ & Psidium guajava $\mathrm{L}$. & Myrtaceae & exótica & 4 & 9 & 8 & $1-2-3$ \\
\hline guanandi & Calophyllum brasiliense Cambess. & Clusiaceae & nativa & 0 & 9 & 5 & 1 \\
\hline $\begin{array}{l}\text { hortelã** } \\
\text { Mentha sp. }\end{array}$ & $\begin{array}{l}\text { Mentha arvensis } \mathrm{L} . \\
\text { Lamiaceae }\end{array}$ & $\begin{array}{l}\text { Lamiaceae } \\
\text { exótica }\end{array}$ & exótica & 7 & 6 & 19 & $2-3$ \\
\hline jacatirão & Tibouchina pulchra Cogn. & Melastomataceae & e nativa & 0 & 6 & 1 & $1-4$ \\
\hline laranja & Citrus aurantium $\mathrm{L}$ & Rutaceae & exótica & 6 & 7 & 6 & $2-3$ \\
\hline limão & $\begin{array}{l}\text { Citrus limon (L.) Burm. F. } \\
\text { Citrus sinensis (L.) Osbeck }\end{array}$ & $\begin{array}{l}\text { Rutaceae } \\
\text { Rutaceae }\end{array}$ & $\begin{array}{l}\text { exótica } \\
\text { exótica }\end{array}$ & 6 & 6 & 2 & $2-3$ \\
\hline $\begin{array}{l}\text { mangue-bravo/ } \\
\text { mangue-vermelho*** }\end{array}$ & Rhizophora mangle L. & Rhizophoraceae & nativa & 0 & 8 & 0 & $1-2$ \\
\hline maracujá & $\begin{array}{l}\text { Passiflora alata Dryand } \\
\text { Passiflora edulis Sims }\end{array}$ & $\begin{array}{l}\text { Passifloraceae } \\
\text { Passifloraceae }\end{array}$ & $\begin{array}{l}\text { nativa } \\
\text { nativa }\end{array}$ & 0 & 3 & 8 & $2-3$ \\
\hline melissa/salva-vida*** & Lippia alba (Mill.) N.E. Br. & Verbenaceae & exótica & 4 & 8 & 2 & 2 \\
\hline mentrasto/tanchais $* * *$ & Plantago australis Lam. & Plantaginaceae & exótica & 0 & 7 & 2 & 2 \\
\hline murta & $\begin{array}{l}\text { Blepharocalyx salicifolius (Kunth) } \\
\text { O. Berg. }\end{array}$ & Myrtaceae & nativa & 0 & 3 & 4 & $1-3$ \\
\hline olho-de-boi & $\begin{array}{l}\text { Eugenia sulcata Spring ex Mart. } \\
\text { indet. } 6\end{array}$ & $\begin{array}{l}\text { Myrtaceae } \\
\text { Fabaceae }\end{array}$ & $\begin{array}{l}\text { nativa } \\
\text { indet. }\end{array}$ & 1 & 4 & 1 & $\begin{array}{c}1-2-* \\
\text { continua }\end{array}$ \\
\hline
\end{tabular}


210 Miranda \& Hanazaki: Conhecimento e uso de recursos vegetais de restinga por comunidades das Ilhas do Cardoso...

Tabela 2 (continuação)

\begin{tabular}{|c|c|c|c|c|c|c|c|}
\hline \multirow[t]{2}{*}{ Etnoespécie } & \multirow[t]{2}{*}{ Espécie botânica } & \multirow[t]{2}{*}{ Família } & \multirow[t]{2}{*}{ Status } & \multicolumn{3}{|c|}{$\mathrm{N}^{\mathrm{o}}$ citações } & \multirow[t]{2}{*}{ Uso } \\
\hline & & & & $\mathrm{N}$ & PI & $\mathrm{FC}$ & \\
\hline palmito & Euterpe edulis L. & Arecaceae & nativa & 0 & 4 & 3 & $1-3$ \\
\hline penicilina & Alternanthera sp. & Amaranthaceae & exótica & 5 & 2 & 2 & $1-2$ \\
\hline picão/pico-pico*** & Bidens pilosa $\mathrm{L}$. & Asteraceae & exótica & 1 & 3 & 3 & 2 \\
\hline pitanga & Eugenia uniflora L. & Myrtaceae & nativa & 5 & 10 & 1 & $2-3$ \\
\hline poejo & Mentha pulegium L. & Lamiaceae & exótica & 0 & 1 & 17 & 2 \\
\hline quebra-pedra & Phyllanthus sp.2 & Euphorbiaceae & nativa & 1 & 7 & 3 & 2 \\
\hline salsa & Petroselinum crispum (Lii.) A.W. Hill & Apiaceae & exótica & 5 & 1 & 0 & $2-3$ \\
\hline timbuva & Pithecellobium langsdorfii Benth. & Mimosaceae & nativa & 0 & 5 & 2 & 1 \\
\hline tucum & Bactris setosa Mart. & Arecaceae & nativa & 0 & 4 & 5 & $1-3$ \\
\hline vacupari & $\begin{array}{l}\text { Garcinia gardneriana (Planch \& } \\
\text { Triana) Zappi }\end{array}$ & Clusiaceae & nativa & 0 & 8 & 9 & $1-3$ \\
\hline
\end{tabular}

* Espécies que não tiveram o uso indicado. Na catalogação das etnoespécies, notaram-se as ocorrências de: a) **homonímia (um mesmo nome popular para designar plantas de espécies diferentes) e b) ***sinonimia (vários nomes populares pelos quais se denominam uma única espécie).

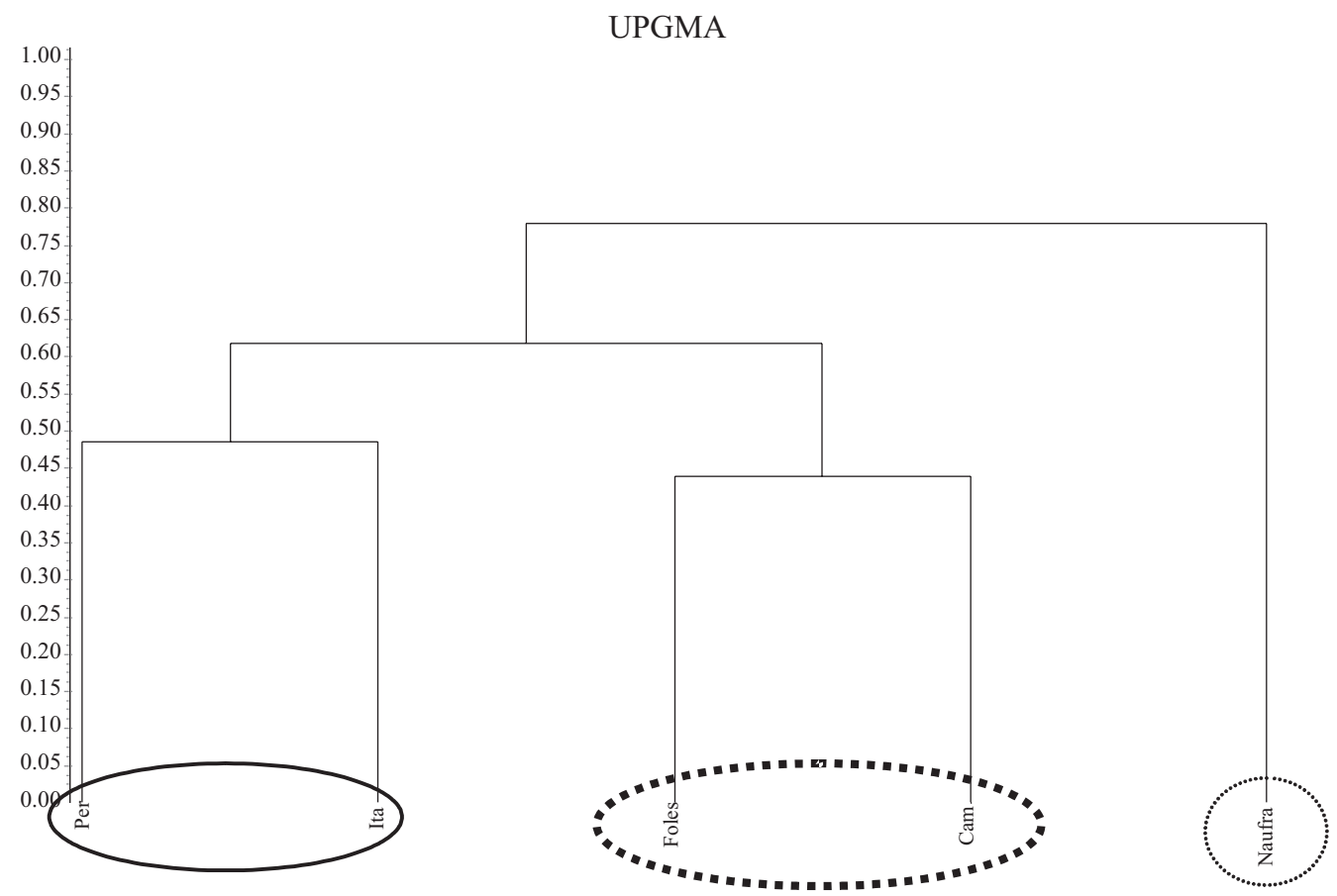

Figura 2. Agrupamento com base no coeficiente de Bray Curtis para as comunidades de Pereirinha (Per), Itacuruçá (Ita), Foles, Cambriú (Cam) e Naufragados (Naufra), utilizando UPGMA (coeficiente de correlação cofenética $=0,958$ ).

(16 espécies), Poaceae (10 espécies), Asteraceae (sete espécies), Fabaceae (seis espécies) e Arecaceae (cinco espécies). Nas comunidades de Cambriú/Foles, as famílias botânicas com maior número de espécies foram Asteraceae, Arecaceae, Poaceae e Myrtaceae (seis espécies cada); Rutaceae (cinco espécies); e Clusiaceae e Euphorbiaceae (quatro espécies cada). Entre os moradores de Naufragados as famílias botânicas que apresentaram maior número de espécies foram Asteraceae (nove espécies); Myrtaceae (cinco espécies); Anacardiaceae (quato espécies); Euphorbiaceae, Liliaceae, Poaceae e Rutaceae (quatro espécies cada).

Comparando os três grupos estudados, foi entre os moradores de Pereirinha/Itacuruçá que foi observado um maior número de etnoespécies e de espécies e famílias botânicas, elevado número de plantas nativas e maior média de citações por entrevista (Tab. 3). Restaram sem identificação em Pereirinha/ Itacuruçá, Cambriú/Foles e Naufragados, respectiva- 


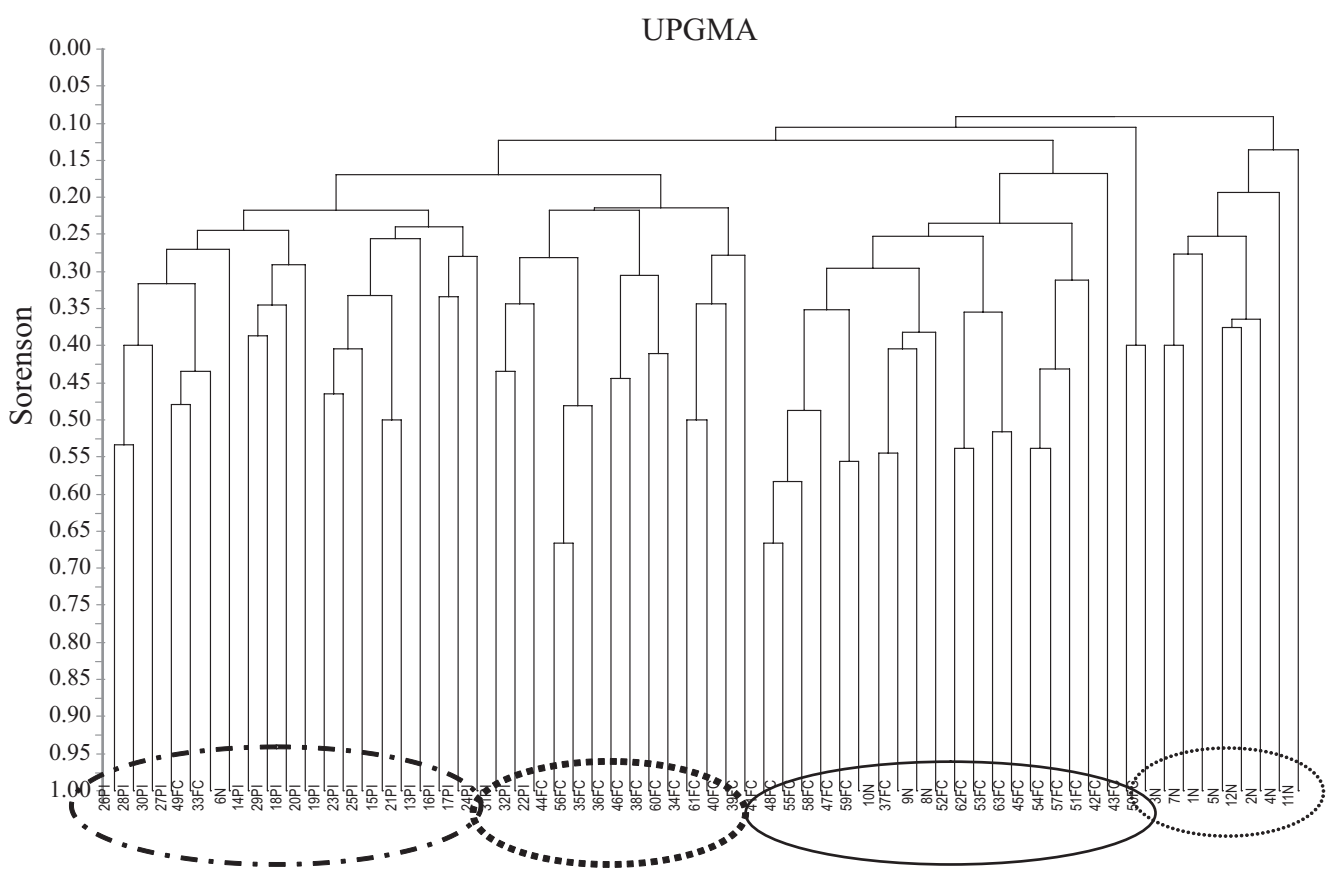

Figura 3. Agrupamento, com base no coeficiente de Sorensen para as comunidades estudadas, utilizando UPGMA (coeficiente de correlação cofenética $=0,62$ ). Os códigos que aparecem na barra inferior correspondem ao número de identificação dos informantes e o respectivo grupo de comunidade $(\mathrm{PI}=$ Pereirinha/Itacuruçá; $\mathrm{FC}=$ Foles/Cambriú; $\mathrm{N}=$ Naufragados).

mente, em relação à espécie: 27, 13 e 16 plantas; à família botânica: 14, 7 e 11 plantas e à origem: 16,10 e 10 plantas.

O segundo grupo, constituído por moradores de Cambriú/Foles, apresentou número menor de etnoespécies e de espécies e famílias botânicas do que
Naufragados, superando, porém, este último, no número de plantas nativas e sendo por ele superado no total de plantas exóticas. O teste chi-quadrado para independência revelou que a quantidade de plantas nativas e exóticas encontradas em cada localidade é diferente $\left(\chi^{2}=50,95, \mathrm{p}<0,05\right.$, a 2 g. 1.). Os resultados

Tabela 3. Características gerais das comunidades estudadas quanto ao conhecimento etnobotânico e comparações de índices de diversidade (Riqueza, Shannon-Wiener e Simpson) e de equitabilidade (Shannon-Wiener e Simpson), para 63 entrevistas na Ilha do Cardoso (SP) e Illha de Santa Catarina (SC), Brasil.

\begin{tabular}{lccc}
\hline Características & Pereirinha-Itacuruçá & Cambriú-Foles & Naufragados \\
\hline Etnoespécies & 156 & 101 & 108 \\
Espécies científicas & 124 & 86 & 93 \\
Famílias botânicas & 57 & 47 & 48 \\
Plantas nativas & 88 & 43 & 24 \\
Plantas exóticas & 36 & 36 & 78 \\
Plantas cultivadas $^{1}$ & 92 & 175 & 148 \\
Plantas não cultivadas $^{1}$ & 373 & 160 & 42 \\
Riqueza (S) $_{\left.\text {Shannon-Wiener }\left(H^{\prime}\right) \text { (base } 10\right)}(156$ & 101 & 108 \\
Equitabilidade Shannon $(E)_{\text {Simpson }(1 / D)}$ & 2,04 & 1,83 & 1,90 \\
Equitabilidade Simpson $\left(E_{1 / D}\right)$ & 0,93 & 0,92 & 0,94 \\
$\quad$ Número de citação & 85,42 & 46,95 & 57,85 \\
Média de citação/entrevista & 0,55 & 0,46 & 0,54 \\
Número de entrevistas & 473 & 340 & 190 \\
\end{tabular}

1 Alguns informantes não responderam à pergunta relativa ao cultivo e das plantas (oito em Pererinha-Itacuruçá e cinco em Cambriú-Foles). Valores dados em número de citação. 
obtidos por Hanazaki et al. (2000) para as comunidades caiçaras de Ponta do Almada e Camboriu (litoral norte de São Paulo) foram semelhantes apenas às comunidades de Pereirinha/Itacuruçá quanto ao número de etnoespécies e de espécies e famílias botânicas.

Nos grupos da Ilha do Cardoso foi maior o número de plantas de restinga e/ou mata de encosta, em relação a Naufragados (Tab. 3). Isto pode refletir uma maior interação com a vegetação nativa, podendo ser explicada por vários fatores complementares, como a distância maior das cidades e do continente da Ilha do Cardoso; a decorrente dificuldade de acesso; as condições de funcionários do PEIC, dedicando-se, por isso, a tarefas que envolvem o ambiente; e o maior tempo de permanência na ilha, de onde muitos são nativos. Já no caso de Naufragados, ressalta-se ainda a composição mais recente de sua população e a sua menor auto-identificação como um grupo cultural distinto e coeso.

Entre as plantas mais citadas por grupo de moradores, verificou-se que em Pereirinha/Itacuruçá as que mais se destacaram foram o guapiruvu/garapuvu (S. parahyba (Vell.) Blake) com $85 \%$ das citações, o araçá ( $P$. cattleyanum Sabine) com $70 \%$; a cataia (Pimenta pseudocaryophyllus (Gomes) Landrum) com 65\%; a caxeta (T. cassinoides (Lam.) A. P. DC.) com $55 \%$ e a pitanga (Eugenia uniflora L.) com $50 \%$. Em Cambriú/Foles sobressaíram o hortelã (M. arvensis L.; Mentha sp. 1), com $61 \%$ das citações; o guapiruvu/garapuvu (S. parahyba (Vell.) Blake) com 58\%; o poejo (Mentha pulegium L.) com 54,8\%; a caxeta (T. cassinoides (Lam.) A. P. DC.) com 41,3\%; o boldo (P. barbatus Andrews; Salvia sp.; indet. 2) com $39 \%$ e a erva-de-santa-maria (Chenopodium ambrosioides L.) com 32\%. Em Naufragados, o boldo ( $P$. barbatus Andrews) com $83 \%$, o capim-limão (Cymbopogon citratus (DC.) Stapf) e o hortelã (M. arvensis L.; Mentha sp. 1) com $58 \%$ cada, foram as plantas mais mencionadas. As principais plantas nativas citadas pelos moradores dos três grupos de localidades foram o araçá/araçároxo ( $P$. cattleyanum Sabine); a pitanga (E. uniflora L.); o caju/caju-branco (A. occidentale L.); o araticum (A. crassifolia Mart.; R. sericea (R.E. Fr.) R.E. Fr.); o quebra-pedra (Phyllanthus sp.2); a erva baleeira/ mentruz/saliana ( $C$. verbenacea $\mathrm{DC}$.) e a aroeira (S. terebinthifolia Raddi).

Algumas das espécies citadas (E. uniflora L., C. citratus (DC.) Stapf, Baccharis trimera (Less.) DC., Persea americana Mill., Musa acuminata Colla, Chenopodium ambrosioides L. e Citrus sinensis (L.)
(Osbeck)) (Tab. 2), ressaltando-se a predominância de exóticas, foram também freqüentemente citadas em outras comunidades caiçaras da Floresta Atlântica, como a Ilha de Búzios (Begossi et al. 1993; 2002a) e as já mencionadas Gamboa (Figueiredo et al. 1993), Almada e Cambrurí (Hanazaki et al. 2000) e Praia Grande (Fonseca-Kruel \& Peixoto 2004). Vale ressaltar que, entre as 32 plantas citadas por $10 \%$ dos moradores da Praia da Almada e Camburí (Hanazaki et al. 2000), 15 figuraram como as mais citadas também entre os grupos aqui estudados.

Uso dos recursos vegetais - Em Pereirinha/Itacuruçá as categorias de uso mais frequentes foram "medicinal" e "manufatura". Comunidades caiçaras estudadas por Figueiredo et al. (1993), Rossato et al. (1999) e Hanazaki et al. (2000) também tiveram essas categorias de uso como as principais. As plantas mais citadas em cada categoria de uso foram, respectivamente, a cataia ( $P$. pseudocaryophyllus (Gomes) Landrum), mencionada por $65 \%(\mathrm{n}=13)$ dos entrevistados e indicada sobretudo como calmante; e o guapuruvu (S. parahyba (Vell.) Blake), utilizado para a fabricação de canoa $(85 \%, \mathrm{n}=17)$. Como alimento destacou-se o araçá ( $P$. cattleyanum Sabine), mencionado por $50 \%$ dos moradores $(n=10)$. Tais plantas são todas nativas de áreas de restinga e/ou mata de encosta.

Em Foles/Cambriú foi superior o número de plantas alimentares, secundadas pelas medicinais, seguidas das usadas para manufatura. As mais citadas por categoria de uso foram: o vacupari (Garcinia gardneriana (Planch. \& Triana) Zappi) (29\%) $(\mathrm{n}=9)$ como o alimento; a hortelã (Mentha sp. 1) $(61 \%)(\mathrm{n}=19)$ como medicinal, indicado no tratamento de resfriados; o guapiruvú (S. parahyba (Vell.) Blake) (55\%) $(\mathrm{n}=17)$ para manufatura, utilizado na fabricação de canoas e para confecção de artesanato. Duas das plantas acima citadas, assim como a maioria das mencionadas nestas localidades, são nativas de áreas de restinga e/ou mata de encosta.

Em Naufragados as categorias de uso mais mencionadas foram alimentar e medicinal. A salsa (Petroselinum crispum (Lii.) A. W. Hill) foi a planta mais citada como alimento ( $42 \%$; $n=5)$, usada como tempero. A que mais se destacou na categoria medicinal foi o boldo ( $P$. barbatus Andrews) $(83 \%$; n = 10), utilizado no tratamento de desarranjos estomacais e distúrbios hepáticos. As categorias de uso de menor expressividade foram "outros" e "manufatura" (Fig. 4). A grande maioria das plantas citadas, incluindo as acima mencionadas, é exótica (Tab. 3). 
Apesar de semelhantes, as comunidades de FolesCambriú e Naufragados diferiram em relação à categoria de uso "manufatura", cuja redução, em Naufragados, desperta a atenção e se contrapõe à categoria "outros" (Fig. 4). O mesmo padrão de uso de Foles-Cambriú e Naufragados foi encontrado entre pescadores artesanais residentes em áreas de Restinga, que apresentaram uma maior citação de espécies alimentares, seguidas das medicinais (Fonseca-Kruel \& Peixoto 2004). A predominância de plantas para uso alimentar nas comunidades de Cambriú/Foles e Naufragados evidencia, sobretudo nesta última, uma maior dependência dos moradores por plantas por eles próprios cultivadas em roças, quintais ou hortas (78\%) ( $\mathrm{n}=190$ citações), apesar da agricultura não ter sido considerada uma atividade de subsistência. Em Pereirinha/Itacuruçá (19\%; $n=473$ citações) e FolesCambriú ( $51 \% ; n=340$ citações), tais percentuais em relação às plantas cultivadas são menores (Tab. 3). As proporções de citações são estatisticamente diferentes entre os grupos de moradores $\left(\chi^{2}=209,22, p<0,01\right.$, 2 g. 1.).

Vale ressaltar que, à semelhança do que ocorre também em outras regiões da Mata Atlântica (Figueiredo et al. 1993; Hanazaki et al. 2000; Begossi et al. 2002; Fonseca-Kruel \& Peixoto 2004), as plantas mais citadas para uso medicinal não são nativas da Mata Atlântica, mas introduzidas, como P. barbatus Andrews, Citrus limon (L.) Burm, C. sinensis L. (Osbeck), C. citratus (DC.) Stapf e Mentha sp.

Análise dos índices de diversidade - Comparando as medidas de diversidade para plantas citadas nos três

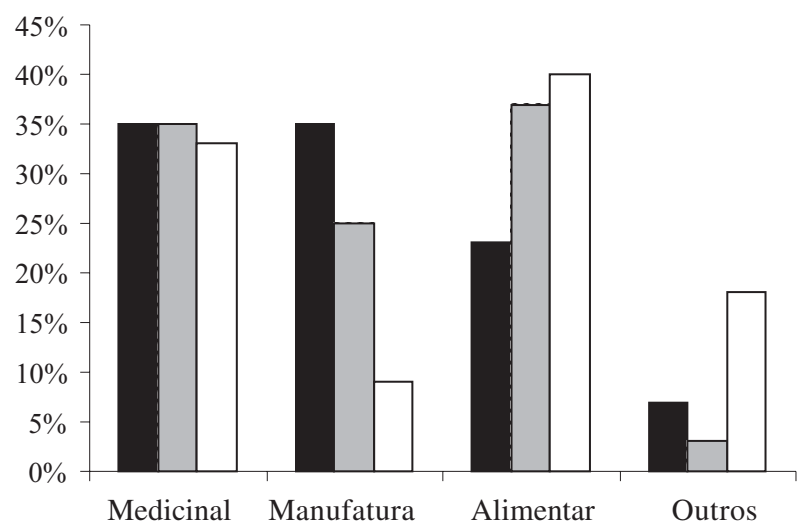

Figura 4. Porcentagens de plantas citadas em cada categoria de uso, por grupo de moradores, para 20 entrevistas em PereirinhaItacuruçá, 31 em Cambriú-Foles e 12 em Naufragados. ( $\square$ = Pereirinha-Itacuruçá; $\square=$ Cambriú-Foles; $\square=$ Naufragados $)$. grupos de moradores nota-se, de maneira geral, uma maior diversidade de plantas citadas pelos moradores de Pereirinha/Itacuruçá. Naufragados apresentou valores intermediários de diversidade, embora não muito diversos do segundo grupo, composto por Cambriú/Foles (Tab. 3). A comparação dos índices de Shannon-Wiener evidenciou uma diferença significativa relativa à diversidade de plantas citadas entre Pereirinha/Itacuruçá e Naufragados $\left(t_{0,05}=44,19\right.$, $\mathrm{p}<0,05,352$ g. 1.), o que também ocorreu entre Cambriú/Foles e Naufragados $\left(t_{0,05}=2,35, \mathrm{p}<0,05\right.$, 440 g. 1.) e entre Pereirinha/Itacuruçá e Cambriú/Foles $\left(t_{0,05}=7,98, \mathrm{p}<0,05,690 \mathrm{~g}\right.$. 1.). As curvas de rarefação ou de riqueza esperada (Fig. 5) confirmam este quadro, mostrando que para um mesmo número de entrevistas esta tendência é mantida.

Os índices de diversidade para plantas conhecidas assemelham-se aos encontrados em outras comunidades caiçaras, no litoral norte do estado de São Paulo, como a Almada (45 entrevistados, $\left.H^{\prime}=1,99,1 / D=67,03\right)$ e Camburi (57 entrevistados, $H^{\prime}=1,98 ; 1 / D=60,23$ ) (Hanazaki et al. 2000). Entretanto Begossi et al. (1993), Figueiredo et al. (1993) e Fonseca-Kruel \& Peixoto (2004) no litoral do Rio de Janeiro, encontraram uma menor diversidade de Shannon, sendo respectivamente $H^{\prime}=1,57, H^{\prime}=1,65$ e $H^{\prime}=1,78$.

O panorama geral de resultados deste trabalho leva-nos a concluir que existem padrões de uso distintos entre os grupos estudados. Os agrupamentos refletem que o modo de vida das comunidades influi no seu conhecimento sobre as plantas, diferenciando-o, mesmo quando habitam áreas onde a disponibilidade dos recursos naturais é similar.

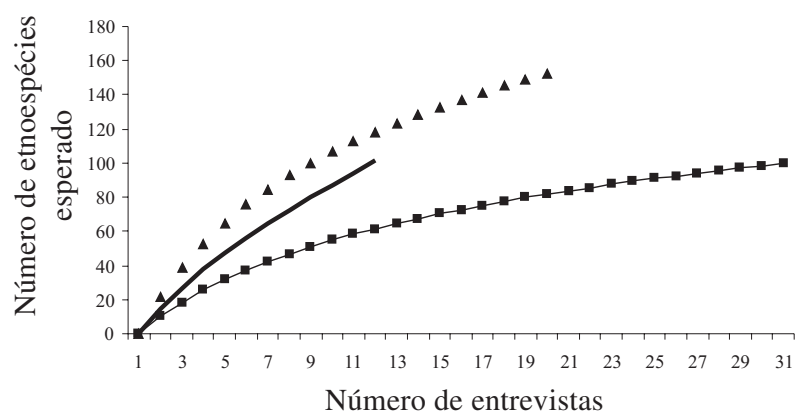

Figura 5. Curvas de riqueza esperada para o total de plantas citadas nas comunidades estudadas, de acordo com o número de entrevistas. ( $\boldsymbol{\Delta}=$ Pereirinha-Itacuruçá; $\boldsymbol{\square}=$ Cambriú-Foles; $\boldsymbol{-}=$ Naufragados). 
A diversidade de plantas conhecidas e utilizadas é maior nas comunidades de Pereirinha/Itacuruçá do que nas de Foles-Cambriú e Naufragados e a maioria das plantas citadas pelos habitantes das primeiras é considerada nativa de áreas de restinga e/ou mata de encosta, além de serem também empregadas para finalidades diversas. Em Cambriú/Foles foi menor a diversidade de plantas citadas, equivalendo à de Naufragados. Entretanto, as plantas ali usadas, como as de Pereirinha/Itacuruçá, são, em sua maioria, nativas da mata circundante e de usos variados. Em Naufragados, as plantas mencionadas são, em grande parte, cultivadas em roças, quintais e/ou hortas e não extraídas da mata para uso, e em relação ao uso das mesmas notou-se que as empregadas para manufatura são muito pouco utilizadas, quando comparadas às dos dois primeiros grupos de moradores.

O quadro descrito permite inferir a maior interação das comunidades da Ilha do Cardoso, especialmente Itacuruçá e Pereirinha, com os recursos vegetais circundantes. Em tais localidades, a maioria dos moradores é composta por funcionários do PEIC que envolvem-se em atividades intimamente relacionadas ao ambiente em que vivem, incluindo o trabalho como guias e monitores ambientais. Dessa forma, além de utilizarem-se da vegetação na sua subsistência, os moradores têm reconhecido e valorizado o seu próprio conhecimento acumulado sobre a natureza.

Em Cambriú/Foles aparentemente há um menor grau de interação com os recursos vegetais nativos, mas em uma situação intermediária entre Pereirinha/ Itacuruçá e Naufragados. Apesar de uma riqueza de espécies menor do que em Naufragados, ainda é maior a proporção de espécies não cultivadas em relação às cultivadas. Finalmente, em Naufragados, o conhecimento dos atuais moradores se restringe praticamente a espécies cultivadas, o que evidencia a pequena interação direta ou dependência do grupo por recursos vegetais do ecossistema de restinga meio ambiente. Se no passado existiram traços característicos da identidade cultural açoriana diretamente ligados à vegetação nativa, atualmente estes parecem ter desaparecido. É possível concluir ainda que, inseridas em ambientes de alta diversidade vegetal, como a Mata Atlântica, nem sempre as comunidades conhecem e utilizam diretamente dos recursos naturais que as circundam.

Os diferentes cenários relativos ao conhecimento etnobotânico sobre recursos vegetais de restinga enfatiza a importância de analisar as particularidades do conhecimento ecológico local. Mesmo em se tratando de comunidades com histórico semelhante e ocupando áreas semelhantes, o conhecimento etnobotânico será em grande parte mediado pelo contexto atual destas comunidades. Dependendo das atividades econômicas praticadas nestas comunidades, este conhecimento pode ser mais ou menos valorizado, permitindo que as condições de produção e reprodução deste conhecimento sejam ou não incentivadas.

\section{Agradecimentos}

À Coordenadoria de Aperfeiçoamento de Pessoal de Nível Superior (CAPES), pela concessão de bolsa de estudos à primeira autora; ao Laboratório de Ecologia Humana e Etnobotânica (UFSC), à FAPESC, aos coordenadores e pesquisadores do Projeto "Diversidade, dinâmica e conservação em florestas do Estado de São Paulo: 40 ha de parcelas permanentes" (ESALQ/USP), ao Programa Biota/FAPESP, pelo apoio logístico e financeiro na execução do trabalho; ao Prof. Dr. Daniel Falkenberg do Departamento de Botânica, UFSC, pelo auxílio na identificação das plantas; ao Dr. Nivaldo Peroni (Fisheries and Food Institute), pelo auxílio nas análises de dados; aos Dr. Gabriela Coelho de Souza, Maria Christina M. Amorozo e Maurício Sedrez dos Reis por comentários e sugestões em uma versão preliminar deste trabalho. Especialmente, aos moradores da Ilha do Cardoso e da comunidade de Naufragados que gentilmente participaram da pesquisa.

\section{Referências bibliográficas}

Albuquerque, U.P. \& Lucena, R.F.P. 2005. Can apparency affect the use of plants by local people in tropical forests? Interciencia 30: 506-511.

Barros, F.; Melo, M.M.R.F. \& Chiea, S.A.C. 1991. Flora fanerogâmica da Ilha do Cardoso: caracterização geral da vegetação e listagem das espécies ocorrentes. v.1. São Paulo, Hucitec.

Begossi, A.; Leitão Filho, H.F. \& Richerson, R.J. 1993. Plant uses in a Brazilian coastal fishing community (Búzios Island). Journal of Ethnobiology 13: 233-256.

Begossi, A. 1996. Use of ecological methods in ethnobotany: diversity indices. Economic Botany 50: 280-289.

Begossi, A. 1998. Knowledge on the use of natural resources contributions to local management. In: C.M. Cotton. Ethnobotany - principles and applications. Chichester, John Wiley Sons.

Begossi, A.; Hanazaki, N. \& Tamashiro, J.Y. 2002a. Medicinal plants in the Atlantic Forest (Brazil) knowledge, use, and conservation. Human Ecology 30: 281-299. 
Begossi, A.; Hanazaki, N. \& Silvano, R.A.M. 2002b. Ecologia humana, etnoecologia e conservação. In: M.C.M. Amorozo; L.C. Ming \& S.M.P. Silva (orgs.). Método de coleta e análise de dados em etnobiologia, etnoecologia e disciplinas correlatas - I Seminário de Etnobiologia e Etnoecologia do Sudeste. Rio Claro, CNPq/UNESP.

Berkes, F.; Folke, C. \& Gadgil, M. 1995. Traditional ecological knowledge, biodiversity, resilience and susteinability. In: C.S. Perrings; K.G. Müler; C. Folke; C.S. Holling \& B.O. Jansson (eds.). Biodiversity conservation: problems and policies. Dordrecht, Kluwer Academic.

Berkes, F. 1999. Context of traditional ecological knowledge. In: F. Berkes. Sacred ecology. Philadelphia, Taylor and Francis.

Blanckaert, I.; Swennen, R.L.; Paredes Flores, M.; Rosas López, R. \& Lira Saade, R. 2004. Floristic composition, plant uses and management practices in homegardens of San Rafael Coxcatlán, Valley of Tehuacán-Cuicatlán, Mexico. Journal of Arid Environments 57: 39-62.

Colwell, R.K. 2005. EstimateS: Statistical estimation of species richness and shared species form samples. Versão 7.5. Disponível em URL< purl.oclc.org/estimates>

Davis, E.W. 1995. Ethnobotany: an old practice, a new discipline. In: R.E. Schultes \& S. von Reis (eds.). Ethnobotany: evolution of a discipline. Portland, Discorides.

Diegues, A.C. \& Arruda, R.S.V. 2001. Saberes tradicionais e biodiversidade no Brasil. Brasília, Ministério do Meio Ambiente.

Falkenberg, D.B. 1999. Aspectos da flora e da vegetação secundária da restinga de Santa Catarina, sul do Brasil. Insula 28: 1-30.

Figueiredo, G.M.; Leitao Filho, H.F. \& Begossi, A. 1993. Ethnobotany of Atlantic Forest coastal communities: diversity of plant uses in Gamboa (Itacuruca Island, Brazil). Human Ecology 21: 419-430.

Fonseca-Kruel, V.S. \& Peixoto, A.L. 2004. Etnobotânica na reserva extrativista marinha de Arraial do Cabo, RJ, Brasil. Acta Botanica Brasilica 18: 77-190.

Hanazaki, N.; Leitao Filho, H. \& Begossi, A. 1996. Uso de recursos na Mata Atlântica o caso da Ponta do Almada (Ubatuba, Brasil). Interciencia 21: 268-276.

Hanazaki, N.; Tamashiro, J.Y.; Leitao Filho, H.F. \& Begossi, A. 2000. Diversity of plants uses in two Caicara communities from the Atlantic Forest coast, Brazil. Biodiversity and Conservation 9: 597-615.

Höft, M.K.; Barik, S.K. \& Lykke, A.M. 1999. Quantitative ethnobotany: applications of multivariate and statistical analyses in ethnobotany. Paris, People and Plants Working Paper.

Krebs, C.J. 1989. Ecological methodology. New York, Harper $\&$ Row.

Lawrence, A.; Phillips, O.L.; Reategui, A.; Lopez, M.; Rose, S.; Wood, D.; José, A. 2005. Local values for harvested forest plants in Madre de Dios, Peru: towards a more contextualized interpretation of quantitative ethnobotanical data. Biodiversity and Conservation 14: 45-79.

Magurran, A. 1988. Ecological diversity and its measurement. London, Croom-Helm.
Ming, L.C. 1996 Coleta de plantas medicinais. In: L.C. Di Stasi (org.). Plantas medicinais arte e ciência. São Paulo, Universidade Estadual Paulista.

Myers, N.; Mittermeier, R.A.; Mittermeier, C.G.; Fonseca, G.A.B.; Kent, J. 2000. Biodiversity hotspots for conservation priorities. Nature 403: 853-858.

Peroni, N. 2002. Coleta e análise de dados quantitativos em etnobiologia: introdução ao uso de métodos multivariados. In: M.C.M. Amorozo; L.C. Ming \& S.M.P. Silva, (orgs.). Método de coleta e análise de dados em etnobiologia, etnoecologia e disciplinas correlates - I Seminário de etnobiologia e etnoecologia do Sudeste. Rio Claro, CNPq/UNESP.

Pieroni, A. \& Quave, C.L. 2005. Traditional pharmacopoeias and medicines among Albanians and Italians is southern Italy: a comparison. Journal of Ethonobiology 101: 258-270.

Prance, G.T.; Baleé, W.; Boom, B.M. \& Carneiro, R.L. 1987. Quantitative ethnobotany and the case for conservation in Amazonia. Conservation Biology 1: 296-310.

Ribeiro, D. 2004. O povo brasileiro: a formação e o sentido do Brasil. São Paulo, Schwarcz.

Rossato, S.C.; Leitão Filho, H.F. \& Begossi, A. 1999. Ethnobotany of caiçaras of the Atlantic Forest coast (Brazil). Economic Botany 53: 377-385.

Sampaio, D.; Souza, V.C.; Oliveira, A.A.; Souza-Paula, J. \& Rodrigues, R.R. 2005. Árvores de restinga: guia ilustrado para identificação das espécies da Ilha do Cardoso. São Paulo, Neotrópica.

Silva, A.J.R. \& Andrade, L.H.C. 2005. Etnobotânica nordestina: estudo comparativo da relação entre comunidades e vegetação na Zona do Litoral - Mata do Estado de Pernambuco, Brasil. Acta Botanica Brasilica 19: 45-60.

Stagegaard, J.; Sørensen, M. \& Kvist, L.P. 2002. Estimations of the importance of plant resources extracted by inhabitants of the Peruvian Amazon flood plains. Perspectives in Plant Ecology, Evolution and Systematics 5: 103-122.

Toledo, V.M.; Batis, A.I.; Becerra, R.; Martinez, E. \& Ramos, C.H. 1995. La selva util: etnobotánica cuantitativa de los grupos indígenas Del trópico húmedo de México. Interciencia 20: 177-187.

Valentin, J.L. 1995. Agrupamento e ordenação. In: P.R. Peres Neto; J.L. Valentin \& F.A.S. Fernadez (eds.). Oecologia Brasiliensis. Volume II: Tópicos em tratamento de dados biológicos. Rio de Janeiro, Universidade Federal do Rio de Janeiro.

Valentin, J.L. 2002. Ecologia numérica: uma introdução à análise multivariadas de dados ecológicos. Rio de Janeiro, Interciência.

Willems, E. 2003. A ilha de Búzios: uma comunidade caiçara no sul do Brasil. São Paulo, Hucitec.

Williams, V.L.; Witkowski, E.T.F. \& Balkwill, K. 2005. Application of diversity indices to appraise plant availability in the traditional medicinal markets of Johannesburg, South Africa. Biodiversity and Conservation 14: 2971-3001.

Zar, J.H. 1996. Biostatistical analysis. London, PrenticeHall. 